\title{
The Standalone and the Portfolio Risk of the Rogers Energy Commodity Index
}

\author{
Samih Antoine Azar \\ Faculty of Business Administration \& Economics, Haigazian University, Beirut, Lebanon \\ Email: samih.azar@haigazian.edu.lb
}

How to cite this paper: Azar, S.A. (2019) The Standalone and the Portfolio Risk of the Rogers Energy Commodity Index. Theoretical Economics Letters, 9, 675-690. https://doi.org/10.4236/tel.2019.94045

Received: January 21, 2019

Accepted: March 26, 2019

Published: March 29, 2019

Copyright (C 2019 by author(s) and Scientific Research Publishing Inc. This work is licensed under the Creative Commons Attribution International License (CC BY 4.0).

http://creativecommons.org/licenses/by/4.0/

\begin{abstract}
This paper tackles the rather recent weekly period from January 18, 2005 to February 28, 2018, encompassing 523 observations. The portfolio is constructed from the perspective either of a US investor or of a Lebanese one, since the US dollar foreign exchange rate was pegged during the above whole period. The portfolio consists of an investment in the US S \& P 500 stock market index and in three Rogers international commodity indexes: agricultural, energy, and metals. The purpose of the paper is to estimate the diversification benefits of the energy commodity index. These benefits arise from the fall in the volatility of the investment portfolio when it is compared to an investment in the energy index only, or in the S \& P 500 only. The procedure follows the seminal approach of Markowitz. The inputs of the model are the variance/covariance matrix, the average log returns, and the condition that all investment shares should sum up to 1 . The outputs, obtained by matrix manipulation, are the optimal investment shares in the four assets, the volatilities of the optimal portfolios, the characteristics of the efficient frontier, the relation between portfolio shares and the expected, or required return, and finally, the predicted Capital Market Line (CML). The evidence shows that, by holding a portfolio composed of the above four assets, the volatilities are substantially reduced. Moreover, and since short sales are allowed in the model, all optimal investment shares in the energy commodity asset are negative, meaning that in the optimal portfolios the positions in the energy index are short positions. The paper points to the significantly high relative riskiness of the energy index, as a stand-alone asset, or as an aggressive and speculative investment on the CML, and to the substantial portfolio benefits of shorting this index.
\end{abstract}

\section{Keywords}

Energy Commodity Index, Risk, Markowitz Diversification, Capital Market Line 


\section{Introduction}

It is no secret that oil assets and energy-derived assets and funds are highly volatile. As a matter of fact, the weekly standard deviation of the Rogers energy commodity index, which is one of the derivative indexes under study in this paper, is $4.64 \%$. Allowing for 50 weeks in a year, the volatility becomes $4.64 \% \times \sqrt{50}=32.81 \%$. This figure compares with a volatility, for the log returns of the S \& P 500, of $16.75 \%$, which is smaller by almost half the volatility of the energy index, and by almost one fourth smaller if variances are compared. In addition, the volatility of gold, another commodity, is $15.34 \%$, again almost half the volatility of the index, and almost one fourth its variance. The figure of $32.81 \%$ is likely to be understated, because an index is usually less volatile than the underlying assets, like oil prices, or other energy components. However, this is not true and is misguided, because the log returns of oil prices figure a volatility of $30.84 \%$, almost the same as the volatility of the energy index of $32.81 \%$. Some individual stocks in the US market do reach a volatility of $70 \%$, but this is the exception rather than the rule.

All these statistics point to the conclusion that oil and energy-related derivative assets are likely to be bad investments if they are considered on a standalone basis. In this regard, the Rogers energy commodity index, used in this paper, has the same average log return as the other assets included in the portfolio, but has also a variance that is statistically and significantly higher.

However, it is by now clear and well known that the risk of an asset depends on its contribution to a well-diversified portfolio, and that covariance between securities is a crucial element in the determination of the overall riskiness of a portfolio. In the limit, portfolio risk is governed by the average covariance, while individual variances drop out from the limiting equation.

This paper does take into consideration diversification spillovers, but, maybe surprisingly, the energy commodity index, which is composed of six liquid futures of energy-related assets, does not fare well either in a portfolio context, or in a standalone context, and is merely not attractive at all. To be precise the index is attractive, and benefits the overall portfolio, only when it is shorted. Although selling short the index is subject to restrictions, among which are liquidity constraints, leveraging, and other regulatory requirements, it is an ideal shorting investment for many hedge funds, which have the necessary financial back-up and stature to implement such a strategy. The fact that there exists a significant and untapped reduction of risk in the financial markets begs the question of the efficiency of these markets. Some other factors are therefore needed to explain this financial discrepancy, or the anomaly of untapped risk reduction.

The paper has many innovative features. As a sub-product the efficient frontier and the tangency portfolio are determined. This tangency portfolio has similar attributes as a US stock market index. Moreover, the derived price of risk is reasonable, and, finally, the Capital Market Line (CML) seems to measure well 
enough the US trade-off between risk and return.

This paper is outlined as follows. After this introduction the methodology is presented in Section 2. This part is mathematical and reviews the statistics from carrying out a Markowitz diversification on the above four assets that were selected to be included in the basic portfolio. The Markowitz quadratic program [1], requires as inputs the variance/covariance matrix and the expected returns on each asset. From these two inputs are calculated all the sample characteristics of interest. The relevant algebraic equations are presented in Section 2, together with some preliminary descriptive statistics of the minimum variance portfolio (MVP). The latter is worth considering because some investors may be inclined to look for a portfolio that has the minimum attainable volatility.

In Section 3, the computed statistics defined in Section 2 are analyzed and some conclusions are drawn. It must be made explicit that the conversion to yearly estimates is necessary because all return and covariance data are computed with a weekly frequency. It is assumed that the year consists of 50 weeks. The results are briefly the following. While the standard deviation of the average portfolio hovers around $16.81 \%$, which is very close to the S \& P 500 standard deviation of $16.75 \%$, the variance of the optimal portfolio, that has the same return, is significantly lower by $20 \%$, although it lies on the inefficient section of the efficient frontier. Since the annualized return of the minimum variance portfolio (MVP) is $4.6 \%$, any return below this figure lies on the inefficient portion of the efficient frontier. The annualized standard deviation of the MVP is $13.91 \%$. The annualized S \& P 500 variance is $40.25 \%$ higher than the variance of the optimal portfolio with the same annualized expected return of $6.52 \%$. The variance on the metals commodity index is more than double, exactly 2.19 times, the variance of the optimal portfolio with the same annualized expected return of $7.25 \%$. Hence portfolio diversification has eliminated a substantial portion of the total volatility, measured in variances. Other regularities will be highlighted in Section 3, the most important of which are the exaggerated standalone risk of the energy index, and the necessity to short this index whatever the return or variance targets. This high risk shows clearly because of the excessively leveraged and speculative location of the energy index on the CML. Specifically this location is way beyond the tangency portfolio, and extremely to its right. At the end, Section 4 summarizes and concludes.

\section{The Mathematics of Markowitz Diversification}

The equations listed in this section can be found in most intermediate finance textbooks. See, for example, Huang and Litzenberger [2] or Danthine and Donaldson [3]. Short selling is allowed. Some definitions are needed. Matrices are in bold while scalars are not:

$\boldsymbol{V}$ : Variance/covariance matrix with $\boldsymbol{V}^{-1}$ being its inverse

$\boldsymbol{w}^{\mathrm{T}}$ : The transpose of the shares of wealth invested in each asset with $\boldsymbol{w}^{\mathrm{T}} \mathbf{1}=1$

$E(\tilde{R})$ : Expected total, or expected required, or target return, on the portfolio 
$\boldsymbol{e}:$ Vector of expected (or average) returns with $E(\tilde{R})=\boldsymbol{w}^{\mathrm{T}} \boldsymbol{e}$

Based upon the above, four scalars are computed:

1) $A=\mathbf{1}^{\mathrm{T}} \boldsymbol{V}^{-1} \boldsymbol{e}=\boldsymbol{e}^{\mathrm{T}} \boldsymbol{V}^{-1} \mathbf{1}=2.373610$

2) $B=\boldsymbol{e}^{\mathrm{T}} \boldsymbol{V}^{-1} \boldsymbol{e}=0.013411$

3) $C=\mathbf{1}^{\mathrm{T}} \boldsymbol{V}^{-1} \mathbf{1}=2583.027599$

4) $D=B C-A^{2}=29.007836$

The Markowitz dynamic program is as follows:

Minimize $\boldsymbol{w}^{\mathrm{T}} \boldsymbol{V} \boldsymbol{w}$ with respect to each $w$

Subject to: $\boldsymbol{w}^{\mathrm{T}} \boldsymbol{e}=E(\tilde{R}) \quad \& \boldsymbol{w}^{\mathrm{T}} \mathbf{1}=1$

Knowing $E(\tilde{R})$ the shares $\boldsymbol{w}$ are computed. The minimum variance portfolio (MVP) has an expected return of $A / C$ and a variance equal to $1 / C$. These are respectively 0.000918925 , and 0.000387143 . Assuming 50 weeks in a year, the annualized return is $4.60 \%$, and the annualized standard deviation is $13.91 \%$.

The equation of the set of frontier portfolios $p$ is equal to:

$$
\sigma_{p}^{2}=\frac{C}{D}\left(E\left(\tilde{R}_{p}\right)-\frac{A}{C}\right)^{2}+\frac{1}{C}
$$

This frontier is a parabola with vertex $(A / C, 1 / C)$ in the expected return/variance space and a hyperbola in the expected return/standard deviation space.

Finally to find the actual average return and the actual variance the following equations are used, with each weight $w$ made equal to $1 / 4=0.25$ :

Average return $=\boldsymbol{w}^{\mathrm{T}} \boldsymbol{e} \&$ portfolio variance $=\boldsymbol{w}^{\mathrm{T}} \boldsymbol{V} \boldsymbol{w}$.

The risk-free rate is assumed to take the following two weekly values: 0.0003 and 0.000731 , both of which are lower than the return on the MVP. This ensures the presence of a tangency portfolio. The annualized rates are respectively $1.5 \%$ and $3.7 \%$. The first rate is the in-sample average of the 3-month euro-dollar interest rate, and the second rate is the average of the 3-month T-bill rates over a long period. The first rate is lower than the second because it includes more weight of recent materializations of the risk-free rate, equaling less than $1 \%$. The tangency portfolio is obtained by maximizing the slope of the tangent to the efficient frontier, using the following equation of the slope:

$$
\theta=\frac{E(\tilde{R})-r f}{\sigma^{2}}
$$

where $r f$ stands for the risk-free rate, and $\sigma^{2}$ stands for the optimal portfolio variance. It is found that $\theta=3.608416$ for $r f=0.0003$, and $\theta=2.946562$ for $r f=0.000731$. These values for $\theta$ can be considered to be estimates of the coefficients of relative risk aversion [4].

The three major inputs to the quadratic program are: the scalar expected return $E(\tilde{R})$, the list of expected returns $\boldsymbol{e}$, and the variance/covariance matrix $\boldsymbol{V}$. The total sample is weekly starting in January 18, 2005, and ending in February 28,2018 , with a total of 523 observations. The S \& P 500 stock market index is retrieved from the web site investing.com, while the Rogers International Commodity Index Energy, Agriculture, and Metal are obtained from the web site of 
www.rogersmaterial.com. The compositions of the three Rogers commodity indexes of futures derivatives are listed in Appendix.

\section{The Empirical Results}

The two inputs, besides the requirement that wealth shares should add up to one, are the variance/covariance matrix, and the return endowments. This matrix is reproduced below, with the diagonal representing the variances of the log returns in the following assets in the sequence: energy index, agricultural index, metal index, and the S \& P 500. The off-diagonal terms are covariances:

$$
\left(\begin{array}{llll}
0.10744 & 0.02265 & 0.03461 & 0.02047 \\
0.02265 & 0.03218 & 0.01756 & 0.01077 \\
0.03461 & 0.01756 & 0.04508 & 0.01325 \\
0.02047 & 0.01077 & 0.01325 & 0.02799
\end{array}\right)
$$

The source of the data is online, and is from the Rogers Commodity web site for the indexes, i.e. from www.rogersmaterial.com, and the data for the S \& $\mathrm{P}$ 500 is retrieved from the web site of investing.com. The second input is the transpose of the vector of the average, in-sample, log returns of these four assets denoted above by the letter $\mathbf{e}$, presented in the same sequence as the variance/ covariance matrix:

$$
\left(\begin{array}{llll}
-0.10505 & -0.01300 & 0.07250 & 0.06515
\end{array}\right)
$$

All these data figures are annualized. It will be assumed throughout that the year is composed of 50 weeks. The actual matrix and vector manipulations are effectuated with weekly data. However, the above is useful to set the minds on the issue.

Table 1 provides for descriptive statistics, and carries out some hypothesis testing. Besides the four assets considered, the descriptive statistics of the minimum variance portfolio and those of the average log return are tabulated. As mentioned previously all data are in a weekly form. The annualized sample means vary between a minimum of $-10.51 \%$, for the energy index, and a maximum of $7.25 \%$, for the metals index. The annualized standard deviations vary between a minimum of $13.93 \%$, for the minimum variance portfolio, and a maximum of $32.81 \%$ for the energy index.

Despite the magnitude of the annualized figures for the means, these are estimated with low precision. And, hence, the major observation is that the null hypothesis that the means are zero fails to be rejected. The test is a t-test, and the maximum value of the absolute $t$-statistics is 1.257664 , which belongs to the log return of the S \& P 500. Likewise the lowest two-tailed p-value is 0.2091 , and this corresponds again to the log return of the S \& P 500.

The second test is a stationarity KPSS test on log returns [5]. All variables fail to reject the null of a zero root. Hence the 4 selected asset variables and the two constructed variables have a stationary mean and variance. Unfortunately all variables reject the null of normality at very low marginal significance levels. The 
Table 1. Descriptive statistics.

\begin{tabular}{|c|c|c|c|c|c|c|}
\hline & energy & agriculture & metals & S \& P 500 & $\begin{array}{l}\text { AVERAGE LOG } \\
\text { RETURN }\end{array}$ & $\begin{array}{l}\text { MINIMUM VARIANCE } \\
\text { RETURN }\end{array}$ \\
\hline Mean & -0.002101 & -0.000255 & 0.001450 & 0.001303 & $9.93 \mathrm{E}-05$ & 0.000919 \\
\hline Median & 0.000640 & -0.001626 & 0.001679 & 0.004153 & 0.001656 & 0.001250 \\
\hline Maximum & 0.138826 & 0.086635 & 0.119094 & 0.082683 & 0.071553 & 0.080197 \\
\hline Minimum & -0.263357 & -0.148017 & -0.136716 & -0.197368 & -0.115617 & -0.164595 \\
\hline Std. Dev. & 0.046400 & 0.025393 & 0.030054 & 0.023686 & 0.023774 & 0.019695 \\
\hline Skewness & -0.603973 & -0.193069 & -0.286449 & -1.721675 & -0.573003 & -1.299906 \\
\hline Kurtosis & 5.426908 & 6.274888 & 5.130094 & 14.47020 & 5.508171 & 14.09615 \\
\hline Jarque-Bera test & 160.1473 & 236.9625 & 106.0276 & 3125.405 & 165.7093 & 2830.380 \\
\hline Probability & $(0.000000)$ & $(0.000000)$ & $(0.000000)$ & $(0.000000)$ & $(0.000000)$ & $(0.000000)$ \\
\hline Sum & -1.098571 & -0.133614 & 0.758602 & 0.681237 & 0.051914 & 0.480417 \\
\hline Observations & 523 & 523 & 523 & 523 & 523 & 523 \\
\hline KPSS test & 0.038269 & 0.044544 & 0.077585 & 0.068780 & 0.045291 & 0.058032 \\
\hline $\begin{array}{l}\mathrm{t} \text {-test on the mean } \\
\text { (2-tailed p-value) }\end{array}$ & $\begin{array}{c}-1.035275 \\
(0.3010)\end{array}$ & $\begin{array}{c}-0.230080 \\
(0.8181)\end{array}$ & $\begin{array}{l}1.103723 \\
(0.2702)\end{array}$ & $\begin{array}{l}1.257664 \\
(0.2091)\end{array}$ & $\begin{array}{l}0.095482 \\
(0.9240)\end{array}$ & $\begin{array}{l}1.066643 \\
(0.2866)\end{array}$ \\
\hline $\begin{array}{c}\text { p-value of the maximum LR } \\
\text { F-statistic }\end{array}$ & 0.2754 & 0.3580 & 0.0639 & 0.1104 & 0.2993 & 0.6098 \\
\hline $\begin{array}{l}\text { Bai-Perron sequential } \\
\text { break test @ 5\% }\end{array}$ & No breaks & No breaks & No breaks & No breaks & No breaks & No breaks \\
\hline
\end{tabular}

Notes: The KPSS unit root test, with a trend, has the null of stationarity. The $10 \%$ asymptotic critical value is 0.119000 for all series. The maximum LR F-statistic is one of the Quandt-Andrews unknown breakpoint tests within 15\% trimmed data. The number of breaks compared is 366 .

test used is the Jarque-Bera Chi-square joint test on the skewness and the kurtosis. The last two tests are for the existence of breaks in the series. No breaks are found using the Quandt-Andrews unknown break test, which is found to have a maximum LR F-statistic having the lowest p-value of 0.0639, and the Bai-Perron sequential break test, which is evaluated at the $5 \%$ marginal significance level. The absence of breaks portends homogeneous samples, and ensures that the results are not driven by instability.

Table 2 provides for bivariate relations between the six assets. The minimum correlation coefficient is 0.358743 (S \& P 500 and Metals index), which carries a $\mathrm{t}$-statistic of 8.77391. And the maximum is 0.840896 (energy index and average return asset), which carries a t-statistic of 35.46544 . Hence all series depend on each other. Therefore, the probability distributions of the populations are inferred to be dependent. This means that the bivariate comparisons, between the average differences, are the appropriate way to proceed. Hence, all the series will be considered matched pairs, and the tests on the pairs are conducted. In general these tests fail to reject the null of zero mean differences, except for the mean difference of the log returns of the energy index and the metals index, which produces an actual p-value of 0.0474 , rejecting the null of zero mean difference at the two-tailed 5\% marginal significance level. 
Table 2. Bivariate relations. Each cell contains sequentially and vertically for all bivariate relations 1) the correlation coefficient, its t-statistic for significance, and its actual p-value, 2) the difference in means, the t-test on a zero mean difference, and its actual p-value, 3 ) the $\mathrm{t}$-test on the equality of variances, and its actual p-value.

\begin{tabular}{|c|c|c|c|c|c|}
\hline & energy & agriculture & metals & S \& P 500 & $\begin{array}{l}\text { AVERAGE } \\
\text { RETURN }\end{array}$ \\
\hline \multirow[t]{8}{*}{ Agriculture } & 0.385140 & & & & \\
\hline & 9.525815 & & & & \\
\hline & 0.0000 & & & & \\
\hline & 0.001845 & & & & \\
\hline & 0.970511 & & & & \\
\hline & 0.3322 & & & & \\
\hline & 9.509182 & & & & \\
\hline & 0.0000 & & & & \\
\hline \multirow[t]{8}{*}{ metals } & 0.497361 & 0.461090 & & & \\
\hline & 13.08575 & 11.86063 & & & \\
\hline & 0.0000 & 0.0000 & & & \\
\hline & 0.003551 & 0.001706 & & & \\
\hline & 1.987754 & 1.342686 & & & \\
\hline & 0.0474 & 0.1800 & & & \\
\hline & 8.958525 & 2.687601 & & & \\
\hline & 0.0000 & 0.0074 & & & \\
\hline \multirow[t]{8}{*}{ S \& P 500} & 0.373191 & 0.358743 & 0.373088 & & \\
\hline & 9.181564 & 8.772391 & 9.178616 & & \\
\hline & 0.0000 & 0.0000 & 0.0000 & & \\
\hline & 0.003403 & 0.001558 & 0.000148 & & \\
\hline & 1.788402 & 1.280487 & 0.110747 & & \\
\hline & 0.0743 & 0.2009 & 0.9119 & & \\
\hline & 8.321865 & 0.959914 & 2.569432 & & \\
\hline & 0.0000 & 0.3375 & 0.0105 & & \\
\hline \multirow[t]{8}{*}{ AVERAGE RETURN } & 0.840896 & 0.690012 & 0.774752 & 0.644854 & \\
\hline & 35.46544 & 21.75999 & 27.96933 & 19.25811 & \\
\hline & 0.0000 & 0.0000 & 0.0000 & 0.0000 & \\
\hline & 0.002200 & 0.000355 & 0.001351 & 0.001203 & \\
\hline & 1.712513 & 0.417868 & 1.625663 & 1.375954 & \\
\hline & 0.0874 & 0.6762 & 0.1046 & 0.1694 & \\
\hline & 18.77881 & 1.577469 & 5.710757 & 0.055220 & \\
\hline & 0.0000 & 0.1153 & 0.0000 & 0.9560 & \\
\hline \multirow[t]{2}{*}{$\begin{array}{c}\text { MINIMUM VARIANCE } \\
\text { RETURN }\end{array}$} & 0.424458 & 0.775588 & 0.655313 & 0.831512 & 0.828404 \\
\hline & 10.70016 & 28.04501 & 19.80228 & 34.16630 & 33.75763 \\
\hline
\end{tabular}




\begin{tabular}{ccccc}
\hline 0.0000 & 0.0000 & 0.0000 & 0.0000 & 0.0000 \\
0.003019 & 0.001174 & 0.000532 & 0.000384 & 0.000819 \\
1.643399 & 1.675038 & 0.535831 & 0.667396 & 1.407032 \\
0.1009 & 0.0945 & 0.5923 & 0.5048 & 0.1600 \\
11.71927 & 4.436881 & 5.306353 & 6.269786 & 3.065092 \\
0.0000 & 0.0000 & 0.0000 & 0.0000 & 0.0023 \\
\hline
\end{tabular}

Table 2 concludes by carrying out variance tests on the bivariate relations. Since all distributions are dependent the usual F-test is invalid. The procedure follows the rather recent paper of Wilcox [6] which builds upon Morgan [7] and Pitman [8]. This is implemented by regressing the two variables, say $\mathrm{X}$ and $\mathrm{Y}$, as $\mathrm{X}-\mathrm{Y}$ as a function of $\mathrm{X}+\mathrm{Y}$, and correcting the standard errors with the HC4 adjustment. The result is a t-test on the slope. Briefly, the energy index has the highest variance, and this variance is significantly higher than all other 5 variables. After that comes the variance of the metals index. The third category is jointly the variances of the $S \& P$ 500, of the agriculture index and the average return asset, which have all insignificantly different bivariate variances. Finally the variance of the minimum variance portfolio has the lowest variance, significantly lower than the other five variables. The main message of these tests, besides the fact that there are four layers of variances, with the energy index on top, followed secondly by the metals index, and then the variances of the agriculture index, the S \& P 500, and the average return asset, followed in the last layer by the variance of the minimum variance portfolio (MVP), this main message is that the energy index has the highest variance, making it the worse standalone investment. The reader is reminded that all average log returns are insignificantly different from zero, so the energy index displays stochastic dominance by the other five assets.

When the minimization of the quadratic program is performed the output produces the shares in each asset as a function of the expected return $E(\tilde{R})$, measured in a weekly frequency. These are:

$$
\begin{gathered}
\text { energy share }=-186.37 E(\tilde{R})+0.120638 \\
\text { agriculture share }=-213.122 E(\tilde{R})+0.569495 \\
\text { metals share }=228.2411 E(\tilde{R})-0.03454 \\
\text { share in S\&P } 500=171.2514 E(\tilde{R})+0.344403
\end{gathered}
$$

It is noticeable from these equations that the share in the S \& P 500 is always positive, as long as the expected return is non-negative. As a matter of fact, the minimum expected return is the risk-free return, which is assumed to be and is usually positive. This means that the position in the S \& P 500 is always long, and is never short. Also it is noticeable that the share in the metals index is nearly always positive too, because the coefficient on the first term is positive 
and the second term is close to zero. Again it seems that the metals index should not be shorted. The share in the agriculture index is zero for a value for $E(\tilde{R})$ of 0.00267 , or $13.36 \%$, in annualized terms. This means that for practically reasonable values for $E(\tilde{R})$ the share in this index is also positive, and rarely shorted. As for the energy index its share is zero for $E(\tilde{R})=0.0006473$, or $3.24 \%$ in annualized terms. Any value for $E(\tilde{R})$ higher that this rate produces a negative share. Since the MVP has a return of 0.00091893 , or $4.60 \%$ in annualized terms, the share in the energy index is never positive. This is illustrated in Figure 1.

Figure 2 portrays the efficient frontier that results from the solution to the quadratic program. The variable on the $\mathrm{x}$-axis is the variance of the portfolio, and the variable on the $y$-axis is the expected return. The efficient frontier has the same shape as found in all finance textbooks. It is a parabola convex to the $\mathrm{y}$-axis. The vertex is the minimum variance portfolio (MVP), which, as already stated has a return of 0.00091893 , or $4.60 \%$ in annualized terms, and a variance of 0.0003871 , or around $1.94 \%$ in annualized terms. Moving from the vertex of the MVP rightward on the curve one draws the efficient frontier, which provides for all portfolios that dominate all others either in terms of expected return, or in terms of variance. For the time being ignore the tangent line to the efficient frontier in this Figure 2.

Although all assets (or portfolios of assets) in Table 1 have average returns that are insignificantly different from zero, three of those assets have a measured return that is negative. They will be compared to the portfolio with a zero average return. These three assets, energy index, agriculture index, and the average return portfolio, are characterized by optimal variances that lie on the lower or inefficient part of the efficient frontier. Assuming that the optimal substitute for these three assets is to match their variances, the three optimal portfolios have respectively expected returns of 0.00537 (26.85\%), 0.00262 (13.1\%), and 0.00230

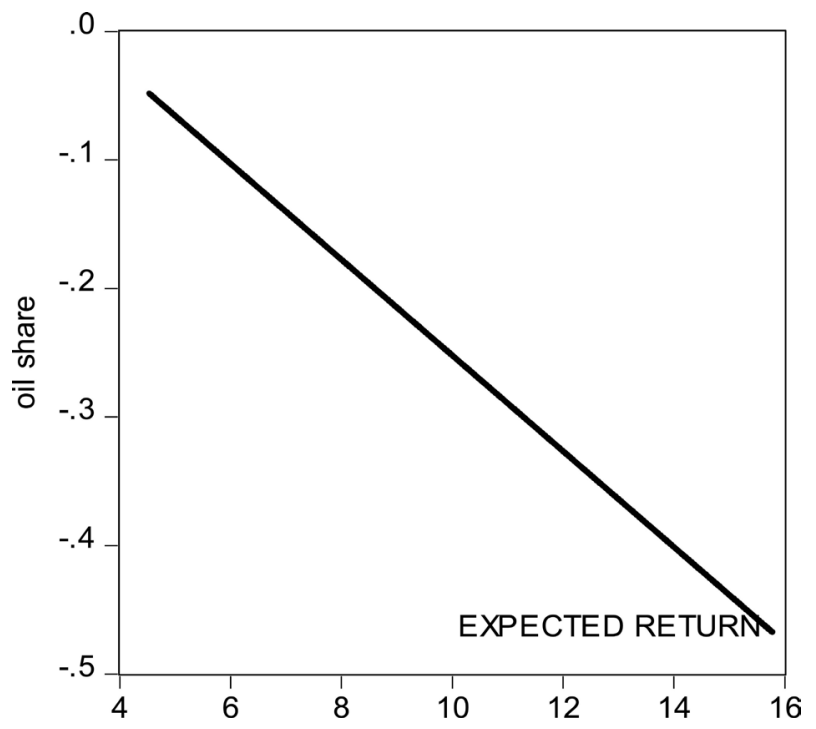

Figure 1. Share of oil in optimal portfolios. 


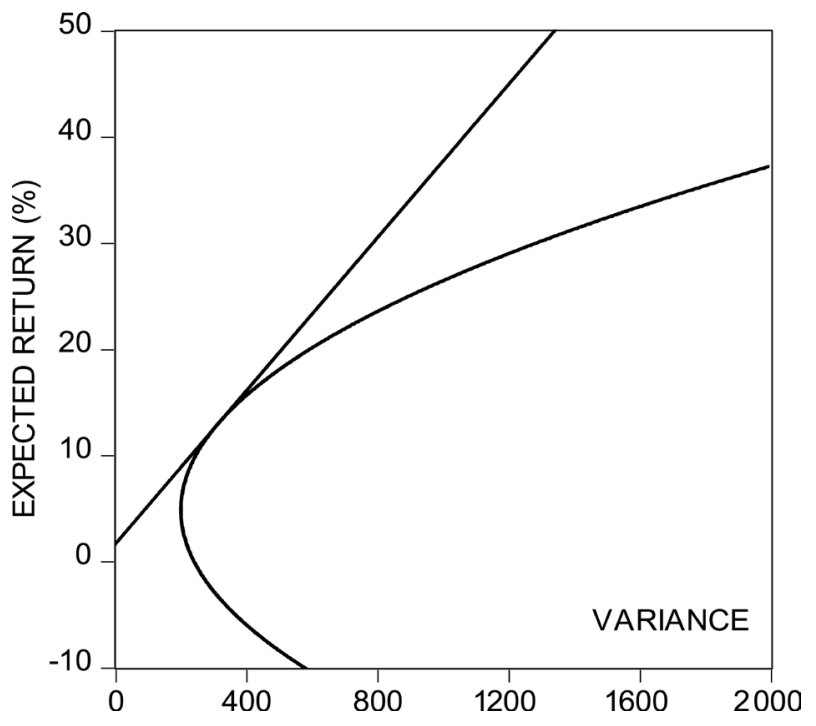

Figure 2. The efficient frontier.

(11.5\%) respectively, with the annualized returns in parentheses. These figures give the extent by which the return on each one of these three assets must increase to become optimal, i.e. on the efficient frontier. By comparison the zero-return portfolio has an optimal return of 0.00180 , if one matches its variance to be optimal, or around $9 \%$ in annualized terms. It is noticeable that the zero-return portfolio has the lowest variance compared to these three assets. This is as expected.

Looking at the two assets that have a positive measured return, the return on the metals commodity index, and that on the S \& P 500 index, the comparison will be performed twice. One is by matching the actual return with the optimal, and the other by matching the actual variance with the optimal. For the S \& $\mathrm{P}$ 500 asset, the optimal return that matches the actual variance with the optimal variance, has an average value of 0.00231 ( $11.55 \%$ annualized), that carries a $\mathrm{t}$-statistic of 2.231072, and a two-tailed p-value of 0.0261, when the hypothesis of a zero return is tested, resulting in rejection of this hypothesis. It is reminded that the actual average return of the energy index is insignificantly different from zero. For the same asset, if one matches the optimal return to the actual return, the resulting variances of the S \& P 500 index (0.000561, or 2.805\% annualized) and the optimal portfolio variance $(0.0004$, or $2.0 \%$ annualized), are significantly different from each other, and that by applying the Wilcox test [6]. This implies that volatility can be significantly lowered by holding the portfolio that mimics the actual portfolio in terms of return. The same result is obtained with the second asset that has a positive measured return, i.e. the metals index. The optimal return is significantly higher by matching the variances, and the optimal variance is significantly lower, by matching the returns. Statistical details on this second asset are available in Table 3.

One remarkable finding in Table 3 is the fact that the share in the energy index is always negative, that the share in the S \& $\mathrm{P} 500$ is always positive and even 
higher than +0.5 , that the share in the agriculture index is close to zero, and, finally that the share in the metals index is always positive. The crucial pattern in this result is that it is optimal to short the energy index in most circumstances.

Figure 2 portrays the efficient frontier together with the tangency portfolio. This portfolio depends on the assumed risk-free rate. If one chooses a rate of $1.56 \%$ per annum, which is the in-sample average Eurodollar rate, one gets the straight line in Figure 2. Figure 3 presents the tangency portfolios from two assumptions of the risk-less rate: $1.56 \%$ as above, and $3.80 \%$, as estimated from long historical data. The second one is flatter as expected.

These tangency portfolios were obtained by maximizing the ratio:

$$
\theta=\frac{E(\tilde{R})-r f}{\sigma_{p}^{2}}
$$

where $E(\tilde{R})$ is the random expected return, $\sigma_{p}^{2}$ is the portfolio variance, and where $r f$ is the fixed risk-free rate. The first tangency line, which happens to

Table 3. Optimal shares in four assets or portfolio of assets.

\begin{tabular}{cccccccc}
\hline Average return (asset) & Actual variance & Optimal variance & Optimal return & energy & S \& P 500 & Agriculture & metals \\
\hline-0.002101 (COM) & 0.002153 & 0.002153 & 0.00537 & -0.880170 & 1.264023 & -0.57497 & 1.191120 \\
-0.000255 (COMA) & 0.000645 & 0.000645 & 0.00262 & -0.367521 & 0.793081 & 0.011114 & 0.563457 \\
-0.0000993 (MEAN) & 0.000565 & 0.000565 & 0.00230 & -0.313605 & 0.743418 & 0.072920 & 0.497267 \\
Zero & 0.000463 & 0.000463 & 0.00180 & -0.222283 & 0.695052 & 0.177350 & 0.385428 \\
0.000919 (MIN VAR) & 0.000387 & 0.0003871 & 0.000919 & -0.050623 & 0.373651 & 0.175202 & 0.501770 \\
0.0013030 (DLSP) & 0.000561 & 0.00040 & 0.001303 & -0.121644 & 0.567029 & 0.292436 & 0.262178 \\
& 0.000561 & 0.000561 & 0.00231 & -0.309880 & 0.739999 & 0.077181 & 0.492702 \\
0.001450 (COMM) & 0.000903 & 0.000412 & 0.00145 & -0.149600 & 0.592717 & 0.26046 & 0.296414 \\
& 0.000903 & 0.000903 & 0.00333 & -0.499970 & 0.914670 & -0.140200 & 0.725508 \\
\hline
\end{tabular}

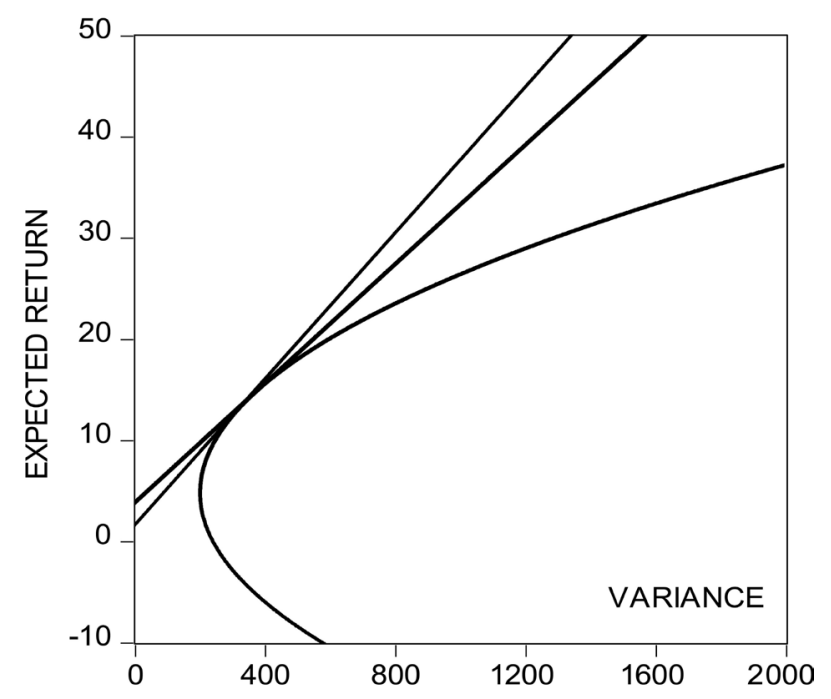

Figure 3. The efficient frontiers. 
be the Capital Market Line (CML) for that specific risk-less return, has an average return of 0.00248 (12.90\% annualized), a figure which is quite close the return on a well-diversified portfolio of common stocks [9]. The fact that the data in this paper result in reasonable values for the tangency portfolio is testimony to the soundness of the model. The second CML with the second estimate of the risk-free rate, carries an average return of 0.00282 (14.66\% annualized), which is still reasonable for the US financial markets. The two estimated slopes of the CAL produce two estimates of the market variance: 0.000604 (3.14\% annualized variance) and 0.000709 (3.69\% annualized variance). These two variances represent the estimates of the variance of the market portfolio. In terms of standard deviations, the figures become $17.72 \%$ and $19.20 \%$ respectively. Again such estimates are quite close to the standard deviation of a well-diversified portfolio of common stocks in the US financial markets. See Table 4.

The price of risk, i.e. $\theta$ is respectively 3.608 and 2.947. These figures measure the coefficient of relative risk aversion, following in that Merton [5], and are quite reasonable. For the two CML lines the share of the energy index is negative, hence this index ought to be shorted. The position is long in the S \& P 500 but to a lesser extent for the metals index. Finally, the share of the agriculture index hovers around zero.

The average return of the energy commodity index is statistically indistinguishable from zero. However the variance of returns is quite elevated. Since the energy index is the main topic of interest in this paper, let us ask the following question: What is the required rate of return for a well-diversified investor to compensate the risk of holding this index? The answer can come from the efficient frontier or from the two estimated CML lines. Table 5 reproduces the answers. The efficient frontier puts a limit of $27.872 \%$ per annum to hold the energy index. According to the first, steeper CAL, the limit is $41.928 \%$. According to the second, flatter CAL line, the required return should be at least $36.790 \%$ per annum. These three estimates measure the excessive magnitude of compensation needed to hold the energy index, given its notoriously high volatility.

Table 4. Tangency portfolios. Annual rates are in brackets. Variances/standard deviations are in parentheses.

\begin{tabular}{|c|c|c|c|c|c|c|c|}
\hline Risk-free rate & Average return & Risk aversion & Optimal variance & energy & S \& P 500 & Agriculture & metals \\
\hline 0.000300 & 0.00248 & 3.608416 & 0.000604 & -0.34156 & 0.7691061 & 0.040951 & 0.531503 \\
\hline$[1.56 \%]$ & [12.90\%] & & $(3.14 \% / 17.72 \%)$ & & & & \\
\hline 0.000731 & 0.00282 & 2.946562 & 0.000709 & -0.40493 & 0.8273316 & -0.031510 & 0.609105 \\
\hline$[3.80 \%]$ & [14.66\%] & & $(3.69 \% / 19.20 \%)$ & & & & \\
\hline
\end{tabular}

Table 5. Statistics on actual and optimal energy commodity index returns.

\begin{tabular}{ccccccc}
\hline \multirow{2}{*}{ Actual variance } & \multicolumn{2}{c}{ Predicted return } & \multicolumn{2}{c}{ Annualized predicted return } & \multicolumn{2}{c}{ Percent improvement in annualized return } \\
\cline { 2 - 6 } & Efficient frontier & Capital market line & Efficient frontier & Capital market line & Efficient frontier & Capital market line \\
\hline 0.002153 & 0.00536 & 0.008063 & $27.872 \%$ & $41.928 \%$ & $38.797 \%$ & $52.853 \%$ \\
0.002153 & 0.00536 & 0.007075 & $27.872 \%$ & $36.790 \%$ & $38.797 \%$ & $47.715 \%$ \\
\hline
\end{tabular}


Table 6 provides answers to a different question: if one investor wants to replicate the second moment of the energy index, and is able to borrow at the risk-free rate, where on the CML should she lie? The answer from the first CML is to have a share of 3.5646 in the market portfolio and a share of -2.5646 of wealth in borrowing the risk-free asset. The answer from the second asset line is a share of 3.0367 in the market portfolio and a share of -2.0367 in borrowing at the risk-free asset. These answers reflect the fact that the optimal required return of the energy index to replicate the risk lies on the upper portion of the CML. Therefore one needs to leverage oneself tremendously in order to hold an investment solely in the energy index. This mirrors the same conclusion for the energy index that this index is highly volatile as an investment whether as standalone or in a portfolio context. If one discounts the convenience yield of being long in oil, for example, the required and optimal return will surely be higher. Although one might conclude that energy securities are not appropriate for investing such a conclusion should be nuanced by the fact that other energy securities provide diversification benefits by being shorted.

\section{Conclusion}

This paper has constructed a small portfolio, consisting of three Rogers commodity indexes together with the S \& P 500 stock market index. The size of the portfolio is adequate as the underlying diagnostics show. The major purpose of the paper is to assess the standing of the Rogers energy commodity derivative index. This assessment is performed by considering the energy index both as a standalone asset, and as an element in a broader portfolio. The results point clearly to the high riskiness and volatility of this index, while its average weekly return is insignificantly different from zero. Compared to the S \& P 500, which has also a zero weekly estimated average return, the energy index departs from the S \& P 500 in its contribution to a portfolio. This is evident because under many scenarios the share of wealth invested in the S \& P 500 is high and positive while the share of the energy index is always negative. This implies that the index should always be shorted. The paper estimates the Capital Market Line (CML) as a by-product. The tangency portfolio seems to conform to expectations from the volatility and return of a well-diversified portfolio of common stocks. The price of risk is also commensurate with expectations. Having identified the efficient frontier and the CML, the investment in the energy index needs a considerable degree of leverage to become attractive and to compensate for the

Table 6. The synthetic two-fund portfolio of the energy commodity index. Annual rates are in parentheses.

\begin{tabular}{cccccc}
\hline Actual variance & Risk-free rate & Share in market return & Share in risk free asset & Portfolio variance & Portfolio return \\
\hline 0.002153 & 0.000300 & 3.5646 & -2.5646 & 0.002153 & 0.008070 \\
$(10.765 \%)$ & $(1.56 \%)$ & & & $(10.765 \%)$ & $(40.35 \%)$ \\
0.002153 & 0.000731 & 3.0367 & -2.0367 & 0.002153 & 0.007075 \\
$(10.765 \%)$ & $(3.80 \%)$ & & & $(10.765 \%)$ & $(35.375 \%)$ \\
\hline
\end{tabular}


volatility. The results show that an annualized average return of $27.87 \%$ is required in order for the index to be part of a long position. The required return is more elevated when one considers the CML: $41.93 \%$ with the steeper CML and $36.79 \%$ for the flatter one. The major conclusion from the paper is that the energy assets are useful only in short positions, and never in long positions. Nonetheless the finding of untapped diversification benefits of shorting the energy index, casts doubt on the efficiency of the financial markets [10] [11]. This could be explained by a home bias, or by the fact that the price of energy is arbitrarily or intentionally manipulated by extraneous and other exogenous forces, or by the liquidity constraints arising from shorting the index. Although this paper studied an energy-related derivative security, the results could be generalized to encompass other energy-related assets, or even, oil prices for instance. The evidence is very strong that all these assets are highly speculative, whether in their standalone, or in a portfolio context, necessitating an aggressive investment approach. These assets are notoriously very bad investment outlets. Policy-wise holding a stock of energy products for speculation does not serve its purpose. Other criteria should be followed to justify such an oil sink. Similarly users of energy assets, like airlines, should keep a low inventory of fuel oil otherwise the riskiness of the business will be magnified to a great extent. In the future, a larger portfolio is recommended and multiple estimates of the variance/ covariance matrix ought to be tried.

\section{Conflicts of Interest}

The author declares no conflicts of interest regarding the publication of this paper.

\section{References}

[1] Markowitz, H. (1952) Portfolio Selection. The Journal of Finance, 7, 77-91.

[2] Huang, C.F. and Litzenberger, R.H. (1988) Foundations for Financial Economics.

[3] Danthine, J.-P. and Donaldson, J. (2015) Intermediate Financial Theory. 3rd Edition, Academic Press, Cambridge.

[4] Merton, R.C. (1980) On Estimating the Expected Return on the Market: An Exploratory Investigation. Journal of Financial Economics, 8, 323-361.

https://doi.org/10.1016/0304-405X(80)90007-0

[5] Kwiatkowski, D., Phillips, P.C., Schmidt, P. and Shin, Y. (1992) Testing the Null Hypothesis of Stationarity against the Alternative of a Unit Root: How Sure Are We That Economic Time Series Have a Unit Root? Journal of Econometrics, 54, 159-178. https://doi.org/10.1016/0304-4076(92)90104-Y

[6] Wilcox, R. (2015) Comparing the Variances of Two Dependent Variables. Journal of Statistical Distributions and Applications, 2, 7. https://doi.org/10.1186/s40488-015-0030-Z

[7] Morgan, W.A. (1939) A Test for the Significance of the Difference between the Two Variances in a Sample from a Normal Bivariate Population. Biometrika, 31, 13-19. https://doi.org/10.2307/2334972

[8] Pitman, E.T.G. (1939) A Note on Normal Correlation. Biometrika, 31, 9-12. 
https://doi.org/10.1093/biomet/31.1-2.9

[9] Brealey, R.A., Myers, S.C. and Allen, F. (2017) Principles of Corporate Finance. International Edition, 12th Edition, McGraw-Hill, New York.

[10] Fama, E.F. (1991) Efficient Capital Markets: II. The Journal of Finance, 46, 15751617. https://doi.org/10.1111/j.1540-6261.1991.tb04636.x

[11] Grossman, S.J. and Stiglitz, J.E. (1980) On the Impossibility of Informationally Efficient Markets. The American Economic Review, 70, 393-408. 


\section{Appendix: Composition of the Rogers International Commodity Indexes}

\begin{tabular}{lr}
\multicolumn{2}{c}{$\begin{array}{c}\text { Energy } \\
\text { RICI }^{\circledR} \text {-E }\end{array}$} \\
Commodity & Rogers International Commodity Index ${ }^{\circledR}$ - Energy \\
Crude Oil & \\
Brent & Allocation \\
Natural Gas & $37.50 \%$ \\
RBOB Gasoline & $32.50 \%$ \\
Heating Oil & $15.00 \%$ \\
Gas Oil & $7.50 \%$ \\
& $4.50 \%$ \\
& $3.00 \%$ \\
& \\
& $100.00 \%$
\end{tabular}

Metals

RICI $^{\circledR}-M^{\mathrm{SM}}$

Commodity

Rogers International Commodity Index ${ }^{\circledR}$ - Metals

Gold

Allocation

Aluminum

$19.92 \%$

Copper

Silver

$15.94 \%$

$15.94 \%$

Lead

$7.97 \%$

Zinc

$7.97 \%$

Platinum

$7.17 \%$

Nickel

$3.98 \%$

Tin

$3.98 \%$

Palladium

$1.20 \%$

$100.00 \%$

Agriculture

Rogers International Commodity Index ${ }^{\circledR}$ - Agriculture

RICI ${ }^{\circledR}-A^{\text {SM }}$

Commodity

Corn

Allocation

$13.61 \%$

Cotton

$12.03 \%$

Soybeans

$10.03 \%$

Wheat Soft Red

$7.88 \%$

Coffee

$5.73 \%$

Live Cattle

$5.73 \%$

Soybean Oil

$5.73 \%$

Milling Wheat

$5.73 \%$

Wheat Hard Red Spring

$2.87 \%$

Sugar

$2.87 \%$

White Sugar

Cocoa

$2.87 \%$

Lean Hogs

$2.87 \%$

$2.87 \%$

Lumber

$2.87 \%$

Rapeseed

$2.87 \%$

Rubber

$2.87 \%$

Wheat Hard Red

$2.87 \%$

Rice

$2.15 \%$

Soybean Meal

$2.15 \%$

Orange Juice

$1.72 \%$

Oats

$1.43 \%$

Milk Class III

$0.29 \%$

$100.00 \%$ 